\title{
The Shopper's Desired Cosmetic-Counter Experience: A Mind Genomics Cartography of Emotions
}

\author{
Howard Moskowitz* \\ Mind Genomics Associates, New York USA and WICE, World Institute of Competitive Excellence, New York, USA \\ ${ }^{\star}$ Corresponding author: Howard Moskowitz, WICE, World Institute of Competitive Excellence, New York, USA
}

Received: December 01, 2021; Accepted: December 22, 2021; Published: December 23, 2021

\begin{abstract}
The study explores the mind of the shopper from the inside out, focusing on motives and interests emerging from the respondent's own perception of herself with respect to an ideal skincare shopping experience. A Mind Genomics cartography (experiment) investigated the phrases that a female cosmetic shopper would use to describe herself in terms of the ultimate skincare shopping experience. Respondents evaluated sixty-three unique vignettes, created from 35 different phases, vignettes created according to a permuted experimental design. The analysis focused on the discovery of 'mind-sets', groups of respondents who showed similar patterns in the element which they felt best escribed them. Three mind-sets emerged: Ebullient, Insecure, and Perfectionist, respectively. A second analysis (scenario analysis) looked at the way five different emotional outcomes (e.g., pleasurable, informative) interacted with the remaining elements. Four of the five emotional outcomes (pleasurable, informative, glamorizing, and therapeutic) interacted with other element, but only among two mind-sets (Ebullient, Perfectionists). There were no interactions for the third mind-set, Insecure, or interactions when the emotional outcome was stated as 'transformative.' The paper shows the potential of deep analysis when the data are collected in a systematized fashion, using permutable experimental designs, and individual-level modeling.
\end{abstract}

\section{Introduction}

If we were to go back 70 years ago, to the beginning of the 1950's, visiting companies manufacturing and marketing cosmetics, we might find an interesting, albeit strange world. It would be a world where there were people whom today we call 'giants', people whose names are on the door, and who are revered for their vision, their inventiveness, their marketing prowess, and for the fact that they are no longer around to prove the opposite. The 1950's, and the war period just before, was the era of the great person. These early giants 'knew' at an intuitive level what the customer wanted, and how to approach the customer. The head of the company might not know how to formulate the product but knew what the customer would like One might do research on customers, perhaps to see who buys, but not for creative purposes. The research would be labelled as sales research, the recitation of 'what happened,' and perhaps 'why'.

At the same time, the advertising industry was promoting the cult of expert as well, not in the creation of the vision for the product, and certainly not the product itself, but rather in the presentation of the product to the public. What to say about the product, what to show about the product, how to communicate the hard-to-communicate emotions and benefits of the cosmetic were left up to the brilliant advertisers of the 1950's, so-called creative geniuses.

The foregoing is by way of introducing our study, something from the middle of the second decade of this $21^{\text {st }}$ century, 60 years later, the span of two-three professional lifetimes, after many of the great cosmetic founds and the legendary advertising genius, built the business, and retired. The focus of this paper is not the past, but the knowledge of today's cosmetic consumer, the 'she' who buys in these still early years of the $21^{\text {st }}$ century.

\section{Asking a Respondent about Herself}

Consumer researcher have realized that people differ dramatically from each, not necessarily in who they are as defined by conventional demographics, but by what they do, and in a much deeper way by who they are. What people do in the world of shopping for cosmetics can be further broken down into where they shop, their self-described motives and shopping behavior, and what they end up buying. For many products, this knowledge suffices. Whether cosmetics enjoy their greatest success at the counter, and should be sold that way, is hard to answer. The success of selling high end cosmetics on the Internet may address the fact that one does not need a profoundly deep understanding of people's mind.

There are papers addressing cosmetic sales at the store counter, and in some case contrasting the sales process with that occurring online. The issue is that the papers give a sense of general differences, but they do not give the specificity, or the insight needed to be translated into business $[1,2]$. For example, we know from the published literature that people define themselves by the products they buy, and in the case of cosmetics, the products that women purchase have symbolic meanings, with these meanings transferred to the purchaser when she uses the product. For example, a superior cosmetic product may enhance a woman's self-esteem when she uses it [3]. Furthermore, as Wu \& Lee (2016) wrote in their paper on impulse buying in cosmetics 
marketing "Cosmetics differ from other retail goods in so far as the 'consumption situation' must influence consumers' 'impulse buying behaviour' through 'experiential marketing' [4]. "In other words, for at least one group (female, unmarried, age 30-35, university degree), it is the experience at the cometic counter in a store which often leads to an impulse purchase.

The foregoing discoveries tell us that it is important to give the cosmetic customer the 'right experience' at the cosmetic counter. That information is helpful. It is in the form of a sociological report or anthropological report. We now know the behavior, observing from the outside in. We know what happens; we know that there is a regular pattern. What we do not know is the specifics, the words, the phrases which address the external behaviors, and perhaps even drive them.

It was towards the goal of a profound understood of the high-end shopper of cosmetics and fragrances that this study was addressed. The reality was that a great deal about how women shop for cosmetics and fragrances were already known, but the different activities, appearing to be similar to each in other when looked at against the vast array of behaviors, were actually radically different. The study was to answer the very practical question of what a high-end shopping experience should be like in the mind of the customer. The approach, Mind Genomics [5] had already been used to explore the 'High End' of semi-luxury items [6], as well as High End perfumes [7].

\section{Mind Genomics}

Mind Genomics is an emerging branch of science focusing on the experience of the everyday, a topic that has not been well explored, despite its ubiquity. The topics of everyday, such as the purchase of cosmetics, are often topics left to business (recording what people buy), to advertising (what persuades), to formulation (what works), and the trade (how to move the product into the hands of the customer). These different groups, business, advertising, and so forth, are not oriented towards developing systematic knowledge of an archival sort, shareable with others, simply because cosmetics are sold for the benefit of the company.

Mind Genomics moves on a different path. With part of its history traceable to experimental psychology, the goal of Mind Genomics is to relate aspects of a topic such as cosmetics to the way people respond. The research strategy is experimentation, where the independent variable is a description of the one's experience with cosmetics, and the dependent variable is a rating $[8,9]$. In this project the focus is on the way the cosmetic experience is described, and the response of people as to whether the description applies to them.

Beyond the experimentation is the use of statistical methods to create ecologically valid test stimuli, viz. combinations, and vignettes. In the ordinary research world, the respondent would be presented with statements about the cosmetic experience, especially the purchasing experience. The statements would be presented one statement at a time The respondent would then rate each phase, each statement about the shopping experience, using a scale to show the degree to which the 'statement applies to me. The problem with the one-at-a-time stimulus is that it forces the respondent to intellectualize the evaluation. Each phrase or test stimulus must be evaluated on the same scale, although the phrases might be of different types (e.g., how I feel when i put on makeup vs what type of experience do i want to when i go shopping). Respondents have a very difficult time maintaining the same criterion for different types of elements. An easier way is to mix the different statements, create small combinations, vignettes, acquire the reactions to the vignettes and deconstruct the reactions to the contributions of the individual elements. This activity might seem convoluted, but it gets around the problem of forcing the respondent to maintain a constant evaluation criterion with radically different elements. The reason the vignette approach works is because the compound description defies simple classification. The respondent ends up using the same criterion for all vignettes, and generally stops trying to outwit the system [10].

\section{Learning 'Who I am as a Cosmetic Shopper' within the Design and Analytic Framework of Mind Genomics}

At the time of the research, qualitative studies with high end shoppers emerged with the obvious finding that shoppers go into stores with different objectives. The earlier work had focused on things under the store's control, and under the manufacturer's control. The focus was on what was being sold, and the messages communicated to different types of customers. The typing of customers was based on then standard psychographics thinking, viz., that there are a limited number of basic 'minds or 'mind-set' who do the shopping. The objective was to identify these basic groups, and to assign each woman shopper to one of these basic groups. Bringing the topic forward, the objective of the study reported here is to understand how the respondent defines herself as a cosmetic shopper, but a shopper who goes to buy cosmetics for different reasons. So, we are interested in the combination WHO she is, and the emotional OUTCOME.

Given the foregoing issues, it appeared possible to apply the Mind Genomics approach with a slight change. The world view of Mind Genomics is the analysis of decisions made about the world of the everyday. The standard Mind Genomics process defines the topic, creates a set of questions which tell a story about the topic, and then generate sets of answers to each question. In most studies the Mind Genomics procedure creates short descriptions of a product or service by combining the answers or elements, doing according to an experimental design. The respondent reads the set of descriptions, the offerings, and responds by separately rating each vignette in the set. The evaluation is usually 'good/bad', 'go/no go', etc. The analysis of Mind Genomics deconstructs the evaluative rating into the partworth contributions of the different answers, the different elements. The process is simple, all of the elements are of the same type, and there is no ambiguity.

When all of elements are 'external' there is no issue. The respondent would be presented with the different combinations messages about the cosmetic purchase situation and instructed to rate the degree to which the combination fits the respondent. The deconstruction of the ratings show how strongly element fits the respondent. The e research 'twist' in this paper involves the measurement of statements about the respondent's predilections, the nature of the behavior at the cosmetic counter, and a phrase about one off five internalized states of feeling about what the purchase experience should create. 
During the early phases of the project, it became increasingly clear that the same person could shop for different reasons at different times. The five different end uses emerged as a range of alternative 'psychological states' that on person might have, albeit at different times. Whether these five states of mind could be separately experienced by one shopper was not of interest. It was sufficient to find out what messages described a person who was in one of the five states. That information was new to the marketing team. The five states about the ultimate skincare shopping experience were pleasurable, informative, glamorizing, therapeutic, or transformative, respectively.

The additional requirement was that the research should not call direct attention to any overall feeling about the shopping experience. The overall feeling should be an element in the study, on par with the other elements. The concern was that in a standard approach using today's tools of market research, the researcher might simply create a matrix, the columns corresponding to the five states of ultimate shopping experience (viz., pleasurable .. transformative), the rows corresponding to different statements about the experience, and then for each column (state of experience), instruct the respondent to check every element which applies, or rate the fit of each element to the each of the five ultimate states of shopping experience. That approach would provide data, it always does. The question was whether the data would be meaningful. Simply asking the respondent to do something, having the respondent fulfill the request, and analyzing the data does not necessarily make the results meaningful.

\section{Research and Analytic Steps Applied by Mind Genomics}

\section{Step 1: Define the Raw Material, Specifically Topic, Questions, and Elements (Answers to the Questions)}

Mind Genomics works by presenting combinations of messages to the respondent and getting the answer. The steps involve the topic, questions which 'tell a story', and a variety of stand-alone phrases which answer questions.

The topic is 'What describes ME. Table 1 shows the seven questions, and the five answers to each question. These questions attempt to tell a story. The requirement to 'tell a story' Is not an absolute requirement. Rather, the idea of telling a story is to provide a framework wherein information can be presented to the respondent in a meaningful and seemingly rational format.

Mind Genomics is flexible. Occasionally, 'stray elements' with no home find themselves inserted into a question. Thus, Question 1 (Describe your skin - what you have, what you want), has four elements about the skin (A1-A4), and room for a fifth element. In that case, A5 was put in (A5: For me it' about staying sexy).It makes no difference as long as the element does not clearly contradict elements from other questions. The structure of questions and answers is done for bookkeeping purposes, and as an aid to the underlying experimental design. The respondents never see the questions. They only see answers, or more accurately, they only see combinations of answers.

The seventh question is the key to the study because it presents five ways of thinking about the ideal experience. There are five such
Table 1: The raw material for the study, comprising seven questions and five elements (answers) for each question.

\begin{tabular}{|c|c|}
\hline & Question 1 - Describe your skin - what you have, what you want \\
\hline A1 & I want perfect skin \\
\hline A2 & I have combination skin \\
\hline A3 & My skin is needy \\
\hline A4 & My skin is unpredictable, always changing \\
\hline \multirow[t]{2}{*}{ A5 } & For me it's about staying sexy \\
\hline & Question 2 - Describe your belief and behavior with regards to makeup \\
\hline B1 & I always put make-up on before I go out \\
\hline B2 & I always want to look like ME, not a made-up version of me \\
\hline B3 & I totally believe in inner beauty! \\
\hline B4 & I believe my face and body are a medium for self-expression \\
\hline \multirow[t]{2}{*}{ B5 } & I need a makeup that taps into my flirty and sensual side \\
\hline & Question 3 - What is your shopping style at the counter \\
\hline $\mathrm{C} 1$ & I like a glamorous make-up look \\
\hline $\mathrm{C} 2$ & My style can be described as conservative \\
\hline $\mathrm{C} 3$ & At the beauty counter, at first I'm usually a little bit shy and stay to myself \\
\hline $\mathrm{C} 4$ & At the beauty counter, I can appear rushed, mistrusting, non-committal \\
\hline C5 & My style... revealing, sexy, with bare, nude, natural make-up \\
\hline D & Question 4- How do you feel and behave at the counter when shopping \\
\hline D1 & I like products that make me feel confident about myself \\
\hline D2 & $\begin{array}{l}\text { When buying a new skincare product... I find it hard to trust the skin-care } \\
\text { consultants }\end{array}$ \\
\hline D3 & At times I feel too nervous to ask questions from beauty consultants \\
\hline D4 & $\begin{array}{l}\text { I can feel bored and lose interest quickly... unless some product captures my } \\
\text { imagination }\end{array}$ \\
\hline \multirow[t]{2}{*}{ D5 } & I'm a more visual shopper... I love touching, smelling, and seeing all the products \\
\hline & $\begin{array}{l}\text { Question } 5 \text {-How do you feel about the consultant and the ambiance of the } \\
\text { counter }\end{array}$ \\
\hline E1 & My challenge is finding the perfect skincare product \\
\hline E2 & $\begin{array}{l}\text { I ask a lot of questions to get all the product details... even though I've done my } \\
\text { own research }\end{array}$ \\
\hline E3 & $\begin{array}{l}\text { I want the beauty consultant to hold my hand, and show me exactly how to use } \\
\text { the products }\end{array}$ \\
\hline $\mathrm{E} 4$ & I am someone who loves to customize make-up in her own unique way \\
\hline \multirow[t]{2}{*}{ E5 } & $\begin{array}{l}\text { I like brightness, colors, fragrance, soft music; variety... I only go into beauty } \\
\text { stores that exude those qualities }\end{array}$ \\
\hline & Question 6-Describe the beauty consultant and how she interacts with you \\
\hline F1 & $\begin{array}{l}\text { I need the beauty consultant to show me the ultimate, top of the line skin-care } \\
\text { range... everything else is a waste of my time }\end{array}$ \\
\hline $\mathrm{F} 2$ & $\begin{array}{l}\text { I want the beauty consultant to use an educational approach, using facts, to } \\
\text { support their claims }\end{array}$ \\
\hline F3 & $\begin{array}{l}\text { I want a "Go To" consultant who knows me intuitively, and can make my } \\
\text { experience more personal each time I return }\end{array}$ \\
\hline F4 & $\begin{array}{l}\text { In an ideal world I'd be left completely alone to look at, touch and try things, } \\
\text { before I am helped }\end{array}$ \\
\hline \multirow[t]{2}{*}{ F5 } & $\begin{array}{l}\text { When I am purchasing makeup, skincare products or fragrances, I like the staff } \\
\text { to be playful, spontaneous, and funny }\end{array}$ \\
\hline & Question 7 - What would you say is your ultimate skincare shopping experience \\
\hline G1 & My ultimate skincare shopping experience is pleasurable \\
\hline G2 & My ultimate skincare shopping experience is informative \\
\hline G3 & My ultimate skincare shopping experience is glamorizing \\
\hline G4 & My ultimate skincare shopping experience is therapeutic \\
\hline G5 & My ultimate skincare shopping experience is transformative \\
\hline
\end{tabular}


ways of thinking, which will play an important role in the analysis. However, at this time, at the start of the study, when the elements are being assembled, Question 7 (What would you say is your ultimate skincare shopping experience) is simply a question, and the answers are simply elements.

\section{Step 2: Create 63 Vignettes or Combinations of Elements Using an Experimental Design}

It is at this point that Mind Genomics departs from more conventional methods. It will be these small combinations of 2-5 elements each that will be evaluated by the respondent, rather than the single element. Figure 1 shows an example of a vignette.

The experimental design ensures that each of the 63 vignettes comprises the appropriate number of elements and the specific combination of elements. The experimental design is nothing more than a prescription for what elements will be combined. The experimental design is created to allow the 63 ratings, one per vignette, from each respondent to be analyzed by OLS (ordinary least-squares) regression at the level of each individual respondent. At the level of the individual respondent all elements appear equally often, no vignette comprises fewer than two elements nor more than five elements, and each respondent evaluates different combinations, because the elements are permuted. That is, the permutation simply changes the code, so that A1 might become A3, A2 become A4, A5 becomes A2 etc. [11].

Figure 1 shows an example of a four-element vignette. The elements are put together without any connectives. The structure of the vignette itself is a set of texts put one below the other, all centered It is easy to graze across the text and assign a rating. The structure of the vignette prevents it from become a densely worded concept. The respondent has no trouble le 'grazing' through the vignette, assigning a rating, and then going on to the next vignette.

\section{Step 3: Create a Rating Scale, and an Orientation Page}

Figure 2 shows the orientation page, and the rating scale. The respondent does not need an introduction to the topic, other than knowing the name of the study, the rating scale (How well does this concept describe YOU?), and some additional house-keeping information. The vignette gives away a little as possible about the nature of the design.

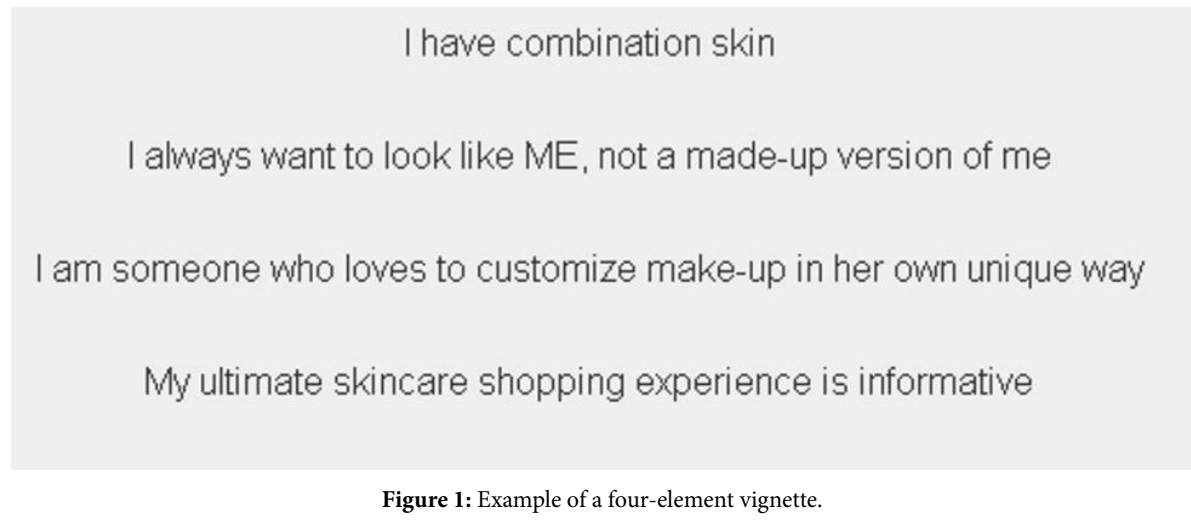

Welcome to the Shopper Profile Survey

We are interested in your opinions about:

\title{
Makeup, Skincare and Fragrance products.
}

\author{
On the following screens, you will be presented with concepts. \\ Please read the concept and answer the question at the bottom of the screen.
}

Although some concepts (screens) may appear similar, please rate each concept independently of any others. Please take your time and read each concept thoroughly and enter your rating based on the following question:

How well does this concept describe YOU?

$1=$ does not describe ME at all

123
45

PLEASE USE THE ENTIRE 1 TO 9 SCALE.

It is not necessary to press the $\angle E N T E R>$ key after entering your rating
$9=$ describes ME very well
8
9

Figure 2: The orientation page with the rating scale. 


\section{Step 4: Invite Respondents to Participate}

The respondents comprise individuals who sign up for so-called 'online panels.' The individuals provide information about which they are their interests, etc. and 'opt in' to participate. With the increasing number of online surveys, working with these panelists has become the preferred method for research. The respondents do the surveys for compensation, but the specific agreement remains a matter between the individual and the online panel company. As a cautionary note, it is usually easier to work with these online panel providers than to source panelists oneself.

\section{Step 5: Acquire the Data and Transform the Data into a Form Usable for Subsequent Analyses}

The actual interview lasts about 10 minutes, with the respondent reading the orientation, and rating the 63 vignettes, followed by a selfprofiling questionnaire.

The respondents rated each of the vignettes on a 9-point scale. Managers who use the data from these types of studies often express difficulty understanding what the ratings mean. Indeed, such difficulties are more widespread than one would like to believe. It is easy to work with an anchored Likert Scale, such as our 1-9 scale, but what does a rating of 4 or 6 or 7 mean? The question is profound. S.S. Stevens, legendary psychophysicist at Harvard University in Experimental Psychology during the years 1938 to 1973, often stated as much, when he averred that one of the hardest problems in science is to convert a continuum to a yes/no (Stevens, 1968, personal communication to author) The issue of the 'best' conversation is deceptively simple until the researcher is faced with a practical issue such as communicating with managers.
The common practice by consumer researchers is to divide this anchored Likert or category scale into two parts, corresponding to NO and YES, respectively. The division point is a matter of personal preference. For this study, the focus was on a stringent definition of 'fits me'. The stringent criterion led to this division: Ratings 1-7 transformed to 0 , and Ratings 8-9 transformed to 100. Following the transformation, a vanishingly small random number was added to the transformed ratings. The magnitude of the number $(<10-5)$ is such that it adds the requisite variation to the rating in case all ratings from a respondent would end up being 1-7 (all transformed to 0) or 8-9 (all transformed to 100). In that case the regression program would simply crash without the miniscule variation introduced by the random number.

Figure 3 shows a preview of the data that will be used for rest of the analysis. A total of 251 women, cosmetic shoppers participated, each evaluated 63 different vignettes. Each respondent generates an average transformed value, which shows us the degree to which the respondent feels that the vignette describes her. The distribution of this average is shown by graph. The average ranges from 0 to 100 , again with each circle corresponding to a respondent.

The figure is broken out into the averages of each of the 251 respondent for those vignettes comprising two elements, three elements, four elements, and five elements, respectively. As the number of elements in the vignette increases, there is a sense conveyed by the graph that a greater number of respondents feel on average that the vignette DOES NOT DESCRIBE THEM (viz., the distribution skews to the left, and the lower averages). As yet, however, we do not know anything about the 'internals' of the vignettes, viz., which elements drive a feeling of 'describes me'.

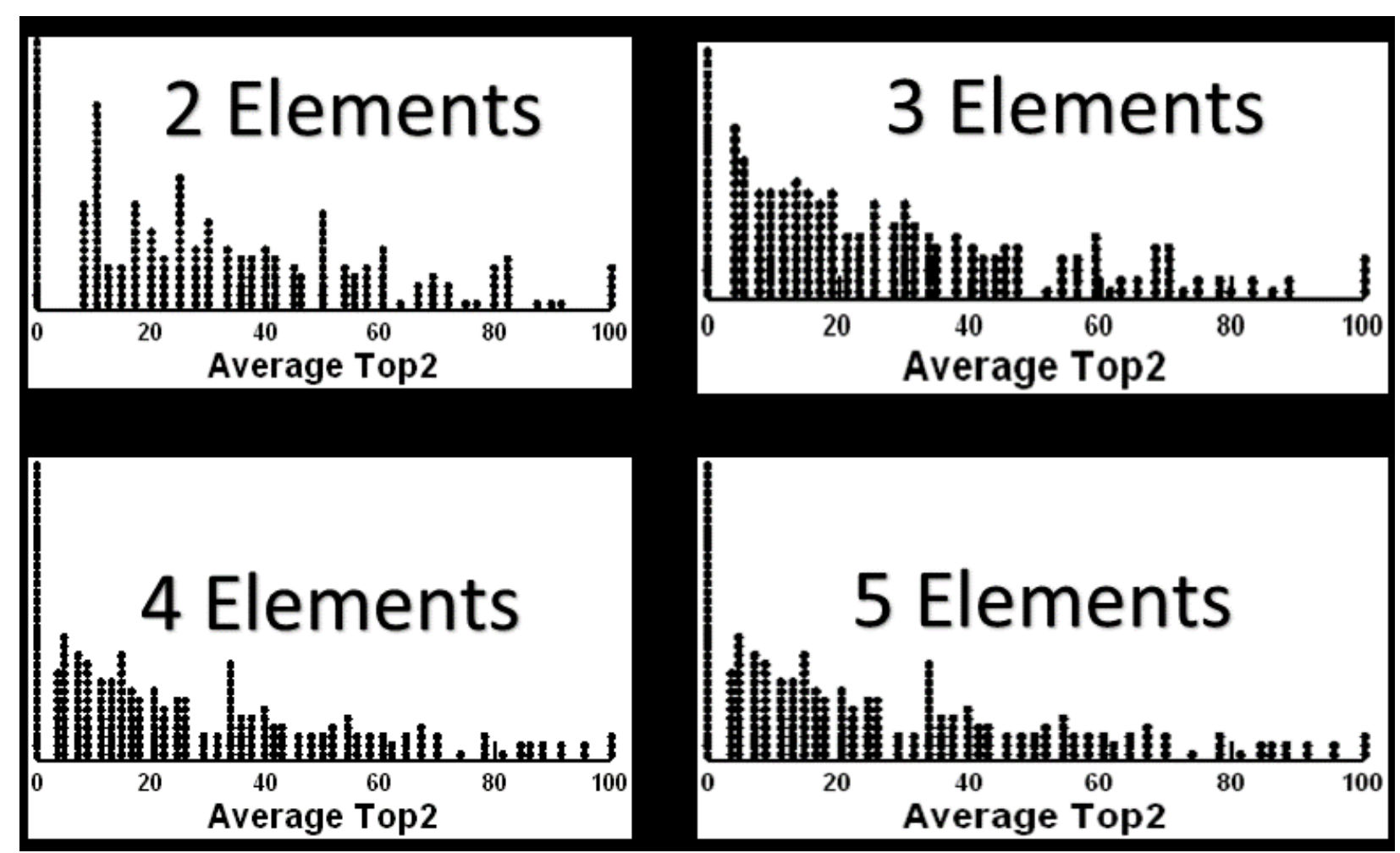

Figure 3: Distribution of average Top2 ratings, by vignettes comprising 2, 3, 4 and 5 elements, respectively. Each point in the graph corresponds to one of the 251 respondents. 


\section{Step 6: Create a Data Matrix Ready for OLS (Ordinary Least- squares) Regression Analysis}

The data matrix comprises 63 rows for each respondent or 15,813 rows for the total panel of 251 respondents. Each row corresponds to a specific vignette, an a specific respone.t

The columns are set up as following:

Column 1 = Column order in the matrix. This is very important, when the researcher wishes to sort the data, and do analyses on certain parts of the matrix. Giving each row an order number allows the researcher to sort the data at the end of the analysis, so the matrix can be returned to its original form.

Column 2 = Respondent identification number (101-351). The respondent identification number is repeated 63 times, once for each vignette.

Column 3 = Order of testing for that panelist (1-63).

Column 4-38 = One column for each element (A1-G5). There are 35 columns for the elements. For each row, the cells in columns 4-38 either have the number ' 0 ' when the element is missing from the vignette corresponding to the row, or the number ' 1 ' when the element is present in the vignette corresponding to the row.

Column 39 -Rating assigned by the respondent on the 9-point scale

Column 40 - The transformed rating from column 39, being either 0 or 100 added to the vanishingly small random number. For ratings of 1-7 the transformed value is 0 . For ratings of 8-9 the transformed value is 100 .

Column 41 - Membership of the respondent in a two-mind-set solution, explained below

Column 42 - Membership of the respondent in a three-mind-set solution, explained below

Remaining columns - classification information about the respondent (age, products used, stores shopped, education, income, etc.).

\section{Step 6: Create a Grand Model for the Full Set of Respondents}

Recall that the variable TOP2 takes on the value 0 when the vignette was assigned the rating 1-7 and takes on the value of 100 when the vignette was assigned the rating $8-9$. The model using all the data is expressed as: TOP2 $=\mathrm{k} 1(\mathrm{~A} 1)+\mathrm{k} 2(\mathrm{~A} 2) \ldots \mathrm{k} 35(\mathrm{G} 5)$.

The foregoing equation comprises 35 terms, one term for each of the 35 elements. The coefficients are the weighting factors. The model does not use an additive constant, the reason being that the model will be used in several different ways, and the elements must have coefficients that are directly comparable to each other, without the contribution of an additive constant. In this way there is no other influence on the magnitude of the coefficients. It is important to note that the coefficients estimated with an additive constant show very similar patterns to the coefficients estimated without an additive constant, as Figure 4 shows.
Table 2 shows the strong performing elements for the total panel. For these models or equations without the additive constant, coefficients of 15 or higher are 'meaningful' from previous observations. Surprisingly, out of 35 elements selected by professionals in the cosmetic business, only three elements emerge as strong performers, strong definers of oneself. This is a remarkable finding. One would have thought that there would be many more strong-performing elements. As the data will suggest, the paucity of strong performing elements may be the consequence of the existence of underlying mind-sets, with different points of view, which end up neutralizing each other in the data from the total panel.

Step 6: Create 251 Individual-level Models, Cluster the Individuals Using the Models, Extract Two and then Three Clusters (Mind-Sets)

A hallmark of Mind Genomics is the use of the data to extract mind-sets, groups of individuals with similar patterns of coefficients. The coefficients, in turn, show how the respondent 'weights' each of the 35 elements to drive the rating of TOP2 (viz., the rating of 100 after the transformation).

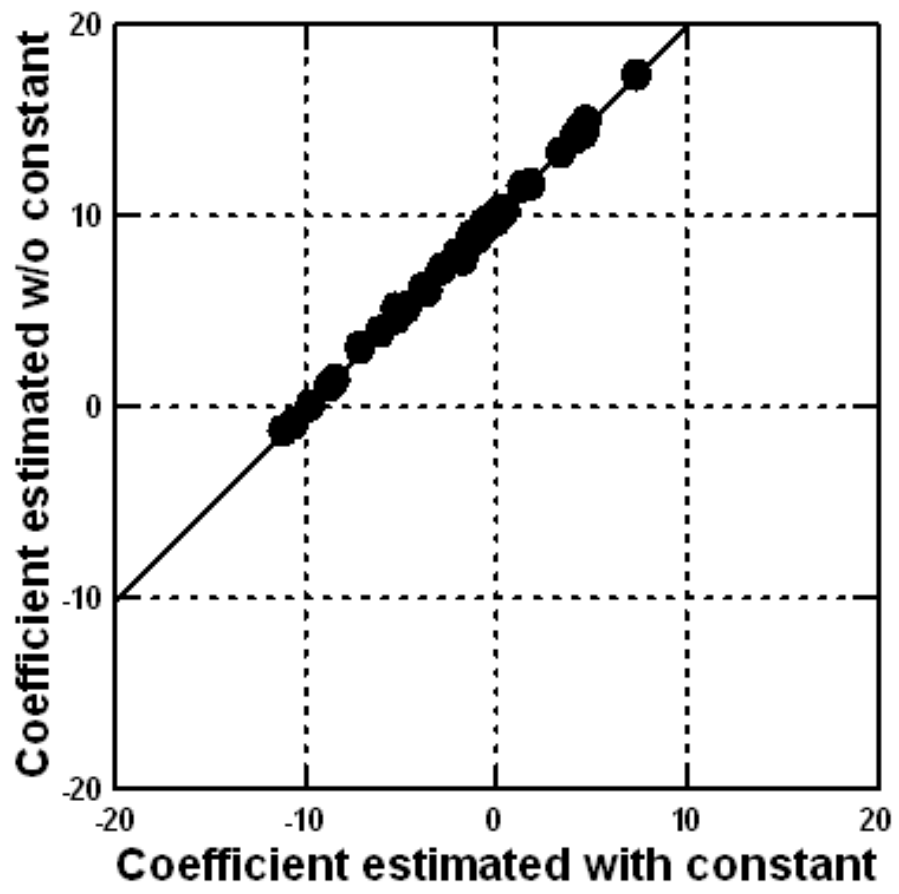

Figure 4: The 35 coefficients for the total panel estimated with an additive constant in the model (abscissa) versus without an additive constant (ordinate).

Table 2: Strong performing elements for the total panel.

\begin{tabular}{|l|l|c|}
\hline & & Strong Performing Elements (Coefficients 15+) \\
\hline D1 & I like products that make me feel confident about myself & 17 \\
\hline B2 & I always want to look like ME, not a made-up version of me & 15 \\
\hline E1 & My challenge is finding the perfect skincare product & 15 \\
\hline
\end{tabular}


A key benefit of the underlying experimental design is that each respondent from the 251 respondents evaluated the precise elements so that the researcher can apply OLS regression to the data from each respondent. This approach produces a matrix of 251 rows, one per respondent, and 35 columns, one per element.

The matrix becomes the basis for clustering, to identify basic groups. Before the clustering, however, the matrix was further subject to statistical analysis, using principal components factor analysis. The 35 variables, viz. the coefficients, were reduced to five independent factors. Each respondent was assigned by the factor analysis to a location in the new five-dimensional space. The locations are defined by the 'factor scores' which differ by respondent, and map to the original 35 coefficients.

The final step in the clustering was to apply k-means clustering to the newly created data matrix comprising 251 rows (one row per respondent) and five columns (one column for each newly created factor). The clustering computed a distance between each pair of the 251 respondents, and located the respondents first into two groups, and then into three groups [12]. The two groups (clusters, mind-sets) could not be easily interpreted because there were too many 'stories' intertwined. The three groups were far more easily to interpret.

Table 3 suggests three different and easy to name mind-sets, each again showing fewer than 35 elements which perform strongly, viz., with a coefficient of 15 or higher. The three mind-sets are distributed across age and income (Table 4).

MS 1 (Exuberant) - A sense of a woman who loves life, and wants to look it, and live it.
MS2 (Insecure) - A person who wants to feel secure. Surprisingly, this mind-set reacts strongly to only one element.

MS3 (Perfectionist) - A person who wants to know what she is doing, and 'get it right'.

Interaction - How end uses acts as 'directors' of the performance of other elements

Ewald \& Moskowitz (2007) introduced the of scenario analysis to understand the interactions among variables [13]. The idea is that elements may interact with each other, affecting the way that respondents respond to the vignette. For example, when the item can have one of several different brands, having one brand in the vignette can set an expectation, whereas having a different brand in the vignette will set a different expectation. The way to discern the effect of the brand on the performance of the elements is to separate the vignettes by brand, thus creating strata, and run the study for each stratum separately in that way it is possible to see how the coefficients of all of the non-brand elements change when the brand changes.

In our study on cosmetics, we have one group of elements, those in Question G, on one's ideal skincare shopping experience. There are five different statements about ultimate experience, ranging from Pleasurable (G1) to Transformative (G5). Tables 2 and 3 suggest that these are not important elements in the mind of the respondent to describe oneself, a perfectly plausible result. The elements deal with the state of mind. Perhaps one does not feel that the ultimate skincare shopping experience is relevant as a descriptor of oneself.

Table 3: Strong performing elements for three emergent mind-sets.

\begin{tabular}{|c|c|c|c|c|}
\hline & TOP2 & 芯 & 忑 & 光 \\
\hline & Mind Set 1 (MS1) Exuberant & & & \\
\hline D1 & I like products that make me feel confident about myself & 21 & 16 & 15 \\
\hline B3 & I totally believe in inner beauty! & 21 & & \\
\hline B2 & I always want to look like ME, not a made-up version of me & 20 & & \\
\hline A1 & I want perfect skin & 17 & & 16 \\
\hline G1 & My ultimate skincare shopping experience is pleasurable & 17 & & \\
\hline D5 & I'm a more visual shopper... I love touching, smelling, and seeing all the products & 17 & & \\
\hline B5 & I need a makeup that taps into my flirty and sensual side & 17 & & \\
\hline B4 & I believe my face and body are a medium for self-expression & 17 & & \\
\hline B1 & I always put make-up on before I go out & 16 & & \\
\hline F5 & When I am purchasing makeup, skincare products or fragrances, I like the staff to be playful, spontaneous, and funny & 16 & & \\
\hline \multirow[t]{2}{*}{ C5 } & My style... revealing, sexy, with bare, nude, natural make-up & 15 & & \\
\hline & Mind-Set 2 (MS2) Insecure & & & \\
\hline \multirow[t]{2}{*}{ D1 } & I like products that make me feel confident about myself & 21 & 16 & 15 \\
\hline & Mind-Set 3 (MS3) Perfectionist & & & \\
\hline E1 & My challenge is finding the perfect skincare product & & & 23 \\
\hline E4 & I am someone who loves to customize make-up in her own unique way & & & 19 \\
\hline F3 & I want a "Go To" consultant who knows me intuitively, and can make my experience more personal each time I return & & & 17 \\
\hline E2 & I ask a lot of questions to get all the product details... even though I've done my own research & & & 16 \\
\hline E5 & I like brightness, colors, fragrance, soft music; variety... I only go into beauty stores that exude those qualities & & & 16 \\
\hline A1 & I want perfect skin & 17 & & 16 \\
\hline F2 & I want the beauty consultant to use an educational approach, using facts, to support their claims & & & 15 \\
\hline
\end{tabular}


In this final analysis of the data, we revisit the ultimate skincare shopping experience, not as an element which varies in competition with four other elements, but rather as a constant, present in all

Table 4: Age and income of the total panel and the three mind-set.

\begin{tabular}{|c|c|c|c|c|}
\hline & $\begin{array}{l}\overrightarrow{0} \\
\dot{\theta}\end{array}$ & 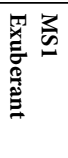 & 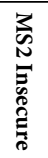 & 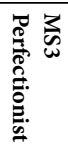 \\
\hline Total & 251 & 78 & 86 & 87 \\
\hline Age 18 to 25 & 15 & 5 & 5 & 5 \\
\hline Age 26 to 30 & 29 & 7 & 10 & 12 \\
\hline Age 31 to 35 & 44 & 15 & 14 & 15 \\
\hline Age 36 to 40 & 34 & 12 & 12 & 10 \\
\hline Age 41 to 45 & 43 & 17 & 9 & 17 \\
\hline Age 46 to 50 & 41 & 10 & 19 & 12 \\
\hline Age 51 to 55 & 45 & 12 & 17 & 16 \\
\hline Income (Thousands) & Total & 1 & 2 & 3 \\
\hline $25-39$ & 21 & 10 & 4 & 7 \\
\hline $40-69$ & 92 & 22 & 36 & 34 \\
\hline 70-99 & 61 & 18 & 18 & 25 \\
\hline $100-129$ & 34 & 8 & 14 & 12 \\
\hline $130-159$ & 23 & 11 & 6 & 6 \\
\hline $160+$ & 20 & 9 & 8 & 3 \\
\hline
\end{tabular}

vignettes in a stratum. The process is straightforward. W first creates six strata of vignettes from the raw data. A stratum comprises all vignettes containing one specific elements from Question G on ideal experience This first step in the scenario analysis is means creating one stratum each for vignettes comprising G1, a second stratum for vignettes comprising G2, etc., and finally a sixth stratum for vignettes absent an element from $\mathrm{G}$, by design.

We run the six regression equations, with only 30 elements (A1F5). The elements G1-G5 are fixed in a stratum. We look at the strong performing elements, operationally defined as 30 or higher. When we do this analysis, we find the following:

1. For each of the five described ultimate skin care shopping experiences, no element reaches 30 when we look at the total panel across the six experiences (G0 and G1-G5).

2. When we look at mind-sets, one experience, 'transformative', fails to produce any element with coefficient of 30 above.

3. When we look at the mind-sets, each mind-set shows specific strong-performing elements.

4. We conclude that there is more to creating mind-sets about what elements drive strong responses. There is the distinct possibility that the focus must be on the combination of topic, mind-set and situation, as shown by Table 5 , specifically by strong performing elements for a mind-set which change according to the stated ultimate skincare shopping experience.

Table 5: Scenario analysis, showing how the ultimate skincare shopping experience, when directly stated in the vignette, can increase the likelihood of a respondent saying, 'it describes me'.

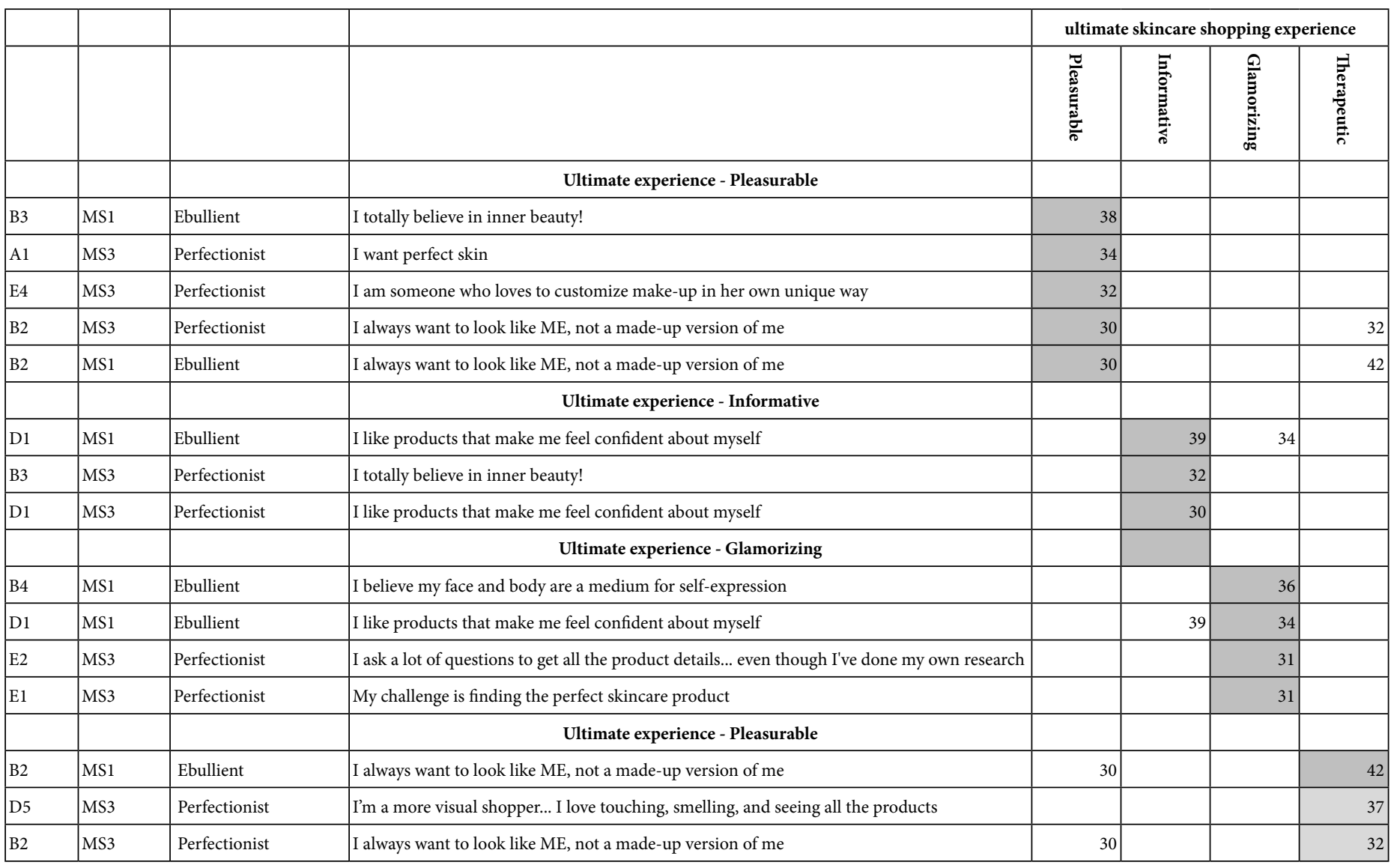




\section{Discussion and Conclusions}

Mind Genomics cartographies were designed for rapid scans of a product or service category, at first to identify what ideas as messages work, but then as way to understand the topic of how a person makes a decision within a specific, granular aspect of life. The early studies, of which this is an example, having been run about ten years ago, in 2012, required the managers, marketers, researchers and sales individuals to structure their thinking, and forced a systematized approach onto what had previously been the domain of the artist marketer or creative advertising professional.

It became clear over time with this study and with others that the experts had a great more knowledge than they were even aware of. There were ideas about what words and phrases worked, and senses of how these strong words and phrases were appropriate or not appropriate for given situations. What became also increasingly obvious was that the knowledge about the desired cosmetic experience was unorganized in the minds of the experts The knowledge was there, as well as the realization that there were profound differences among women in the way they shopped. Knowledge of this profound knowledge emerged as anecdotal, for the simple reason that the world of cosmetics (and fragrances) operated at two levels. At the very concrete level, there were product tests, and attitude and usage questions about brands, and feelings. The product tests were done on an as-needed basis, with technical reporting needed for product design and development. At a higher level was the tracking studies, about products used, feelings toward products, towards the category, and so forth. The results of these high-level studies emerged as charts, with a lot of trends, but very little specific information that could be used 'as needed', in an off-the-shelf format.

The data tables in this paper suggest immediately that there is a fertile field to be planted and tilled. This field comprises the systematic analysis of messaging, not simply to show to the 'client' that one's creative 'works, but rather a database which can drive new and important insights. The time has now arrived for the business community to invest in the systematic data basing of communications, phrases, not at the level of 20,000 feet, couched in generalities and endless tables, but rather in simple-to-use data created at the level of granular experience. The contribution of Mind Genomics to that prospect is a simple system, template (see www.BimiLeap.com), with rapid turnaround (hours), and of low cost and low risk. The study on cosmetics is simply one more example of what can be accomplished in a short time, with little effort.

\section{References}

1. Hong BS, Kwon YJ, Park SH, Paik IS (2008) The effects of relational benefits and commitment on word-of-mouth intention and repurchase intention for cosmetic purchaser in internet shopping mall. Journal of the Korean Society of Clothing and Textiles 32: 1202-1212.

2. Tajuddin K, Nikdavoodi JN (2014) Cosmetic buying behavior: examining the effective factors. Journal of Global Scholars of Marketing Science 24: 395-410.

3. Kalender GI (2021) The symbol of cosmetic products as social distinction and the false needs of shopping for cosmetics at department stores aroused by women's magazines. Advances in Journalism and Communication 9: 1-11.

4. Wu P, Lee CJ (2016) Impulse buying behaviour in cosmetics marketing activities, Total Quality Management \& Business Excellence 27: 1091-1111.
5. Moskowitz HR, Gofman A (2007) Selling Blue Elephants: How to Make Great Products that People Want Before They Even Know They Want Them. Pearson Education.

6. Bevolo M, Gofman A, Moskowitz HR (2012) Premium by Design: How to Understand, Design and Market High End Products. Gower Publishing, Ltd.

7. Horoszko N, Moskowitz D, Moskowitz H (2018) Discovering and pinpointing the brand DNA of five great perfume brands. In Understanding the Marketing Exceptionality of Prestige Perfumes (pp. 26-73). Routledge.

8. Milutinovic V, Salom J (2016) Mind Genomics: A Guide to Data-Driven Marketing Strategy. Springer.

9. Moskowitz HR, Gofman A, Beckley J, Ashman H (2006) Founding a new science: Mind genomics. Journal of Sensory Studies 21: 266-307.

10. Porretta S, Gere A, Radványi D, Moskowitz H (2019) Mind Genomics (Conjoint Analysis): The new concept research in the analysis of consumer behaviour and choice. Trends in Food Science \& Technology 84: 29-33.

11. Gofman A, Moskowitz H (2010) Isomorphic permuted experimental designs and their application in conjoint analysis. Journal of Sensory Studies 25: 127-145.

12. Likas A, Vlassis N, Verbeek JJ (2003) The global k-means clustering algorithm. Pattern Recognition 36: 451-461.

13. Ewald J, Moskowitz HR (2007) Market forces: The push-pull of marketing and advertising in the new product business. Chapter 8 103-122.In: Accelerating New Food Product Design and Development (ed. J.H. Beckley, M.M. Foley, E.J. Topp, J.C. Huang \& W. Prinyawiwatkul), Blackwell Publishing and the Institute of Food Technologists, Chicago.
Citation:

Moskowitz H (2021) The Shopper's Desired Cosmetic-Counter Experience: A Mind Genomics Cartography of Emotions. ARCH Women Health Care Volume 4(5): $1-9$. 